\title{
EL EMPLEO TEMPORAL EN LAS ADMINISTRACIONES PÚBLICAS: LIIMITES, PREVENCIÓN Y SANCIÓN A SU UTILIZACIÓN ABUSIVA
}

\author{
Temporary employment in public Administrations: \\ limits, prevention and penalties regarding its excessive use
}

FRANCISCO JAVIER ARRIETA IDIAKEZ*

Universidad de Deusto, España

\section{RESUMEN}

El objetivo principal de este artículo es determinar si en España existen medidas para prevenir y, en su caso, sancionar el uso abusivo del empleo temporal en las Administraciones públicas. Para ello, en primer lugar, se analizarán las distintas modalidades de empleo temporal que existen en las Administraciones públicas, profundizando, en especial, en la figura del contrato indefinido no fijo, debido a las dudas que genera. En segundo lugar, se abordarán los límites al empleo temporal en las Administraciones públicas que se regulan tanto en la Directiva 1999/70 como en el Derecho interno. Finalmente, se centrará la atención en determinar si en España existen medidas adecuadas para prevenir y, en su caso, sancionar los abusos derivados de la utilización de sucesivos contratos de duración determinada. A tal efecto, se analizarán la normativa interna y la jurisprudencia del TJUE.

Palabras clave: Administraciones públicas, empleo temporal, contrato indefinido no fijo, prevención, sanciones.

\section{ABSTRACT}

The main purpose of this paper resides in determining whether Spain has means to prevent and, in this case, penalise the excessive use of temporary employment in public administrations. To that end, firstly, we will analyse the existing forms of temporary employment in public administrations and, in particular, we will delve into the figure of the non-permanent indefinite contract, due to the doubts that it generates. Secondly, we will address the limits to the temporary employment in public administrations that are regulated both in the Directive 1999/70 and in domestic law. Finally, we will focus the attention on determining if Spain has adequate measures to prevent and, in this case, to penalise the abuses derived from the use of consecutive fixed-term contracts. To that end, we will analyse both national law and the case law of the European Court of Justice.

Keywords: Public administrations; temporary employment; non-permanent indefinite contract; prevention; penalties.

* Correspondencia a: Francisco Javier Arrieta Idiakez. Facultad de Derecho. Universidad de Deusto. Avda. de las Universidades 24, 48007-Bilbao (España) - javier.arrieta@deusto.es - https://orcid.org/0000-0003-4696-6356

Cómo citar: Arrieta Idiakez, Francisco Javier. (2020). «El empleo temporal en las administraciones públicas: límites, prevención y sanción a su utilización abusiva»; Lan Harremanak, 43, 41-72. (https://doi.org/10.1387/lan-harremanak.21784).

Recibido: 03 junio, 2020; aceptado: 19 junio, 2020.

ISSN 1575-7048 - elSSN 2444-5819 / (c) 2020 UPV/EHU 


\section{El empleo temporal en las Administraciones públicas}

Los problemas de la temporalidad en las Administraciones públicas se advertían incluso con anterioridad a la aprobación de la Ley 7/2007, de 12 de abril del Estatuto Básico del Empleado Público (BOE de 13 de abril de 2007, núm. 89).

Así, el Informe de la Comisión para el estudio y preparación del Estatuto Básico del empleado público (Instituto Nacional de Administración Pública, 2005) al abordar las clases de empleados públicos (cfr. capítulo V), y referirse a la «situación actual y problemas a resolver» (cfr. apartado 16), señala que (p. 48):

Un (...) problema, que se ha agravado en los últimos tiempos, es el abuso de la temporalidad en el empleo público, que, según los datos estadísticos disponibles -informe del Consejo Económico y Social, La temporalidad en el empleo en el sector público, diciembre de 2004-, alcanza en la actualidad a más del 22,8 por 100 del conjunto de los empleados públicos, en las Corporaciones Locales a más del 30 por 100 y en la sanidad, a casi el 30 por $100(\ldots)$.

Igualmente, al referirse al personal laboral de carácter temporal, el Informe alude a la necesidad de «abordar el problema de la contratación temporal irregular» (p. 57).

En ese sentido, el Informe dedica su apartado 23 a la «Necesidad de abordar el problema de la elevada temporalidad existente en el empleo público», y, a la luz, de dos informes, a saber, el informe del Defensor del Pueblo titulado Funcionarios interinos y personal eventual: la provisionalidad y temporalidad en el empleo público (2003), y el informe del Consejo Económico y Social anteriormente mencionado, concluye que:

El volumen de temporalidad hoy existente en el sector público parece exceder del que sería razonable para atender a las necesidades temporales de prestación de servicios y actividades públicas de las distintas Administraciones y que, en realidad, se formalizan como interinidades o contrataciones temporales actividades que responden a necesidades permanentes y que se prolongan o reiteran año tras año. Una parte importante de esa temporalidad tiene, por tanto, un carácter ficticio o artificial.

Actualmente, según la EPA del primer cuatrimestre de 2020 los temporales representan el 27,5\% del personal laboral, siendo dicho porcentaje 3 puntos más elevado que en el sector privado. Por su parte, según el último Boletín Estadístico del Personal al Servicio de las Administraciones Públicas publicado, que corresponde a julio de 2019, en el conjunto de las Administraciones públicas, el $56 \%$ es personal funcionario de carrera, el $22,4 \%$ es personal laboral y el resto del personal (personal funcionario interino, personal eventual y otro personal) supone el $21,60 \%$. 
Precisamente, para abordar el problema de la elevada temporalidad que presenta el empleo en las Administraciones públicas, y determinar los límites regulados al respecto, así como las medidas de prevención y, en su caso, sanción, previamente, es fundamental delimitar las distintas modalidades de empleo temporal. No se trata de una cuestión baladí, en tanto en cuanto las dudas más frecuentes en materia de empleo público son las relativas al correcto uso de las distintas modalidades de contratación temporal; más aún, como se verá (infra 1.1.2), teniendo en cuenta las serias consecuencias de los errores cometidos (Villanueva Puertollano, 2012: 151).

Así, el empleo temporal en las Administraciones Públicas puede traer causa, como sucede en las empresas privadas, de una incorporación o gestión directa o indirecta de personal. Es decir, se parte de la idea de que para afrontar la temporalidad en las Administraciones Públicas es necesario no sólo contemplar a los empleados públicos de carácter temporal que son empleados como tales directamente por la Administración, sino que también a aquellos empleados que, sin pertenecer inicialmente a la Administración, comienzan prestando servicios de carácter temporal para la misma a través de distintos negocios jurídicos, y, por distintos motivos, acaban incorporándose a la Administración, convirtiéndose en empleados públicos de carácter temporal. De ahí que, a continuación, se proceda a realizar una clasificación en función de dicha diferenciación.

\subsection{El empleo temporal en las Administraciones públicas por incorporación o gestión directa}

A continuación, se diferenciarán, en lo que se refiere al empleo temporal en las Administraciones públicas, las distintas modalidades de incorporación o gestión directa. Así, en primer lugar, se analizarán los contratos laborales temporales. Pese a su carácter laboral, en segundo lugar, se dedicará un apartado específico al personal indefinido no fijo, debido a las particularidades que presenta y dudas que genera en la práctica. En tercer lugar, se centrará la atención en los funcionarios interinos. En cuarto lugar, se tratará la figura del personal eventual. En quinto y último lugar, se hará referencia al personal estatutario temporal.

\section{a) Los contratos laborales}

Conforme a lo establecido en los artículos 8.2.c) y 11.1 del Real Decreto Legislativo 5/2015, de 30 de octubre, por el que se aprueba el texto refundido de la Ley del Estatuto Básico del Empleado Público (TRLEBEP) (BOE de 31 de octubre de 2015), las Administraciones públicas pueden utilizar los contratos de trabajo de carácter temporal regulados por la legislación laboral, es decir, el contrato por obra o servicio determinado, el contrato eventual y el contrato de interinidad. Es más, estos contratos deben regirse, como regla general, por lo establecido en el artículo 15 del Real Decreto Legislativo 2/2015, de 23 de oc- 
tubre, por el que se aprueba el texto refundido de la Ley del Estatuto de los Trabajadores (TRLET) (BOE de 24 de octubre de 2015, núm. 255) y en el Real Decreto 2720/1998, de 18 de septiembre, por el que se desarrolla dicho precepto (BOE de 8 de enero de 1999, núm. 7).

Como se verá, las particularidades se refieren en el ámbito de las Administraciones públicas a las consecuencias derivadas del hecho de celebrar dichos contratos en fraude de ley (infra 1.1.2), de superar la duración máxima del contrato por obra o servicio determinado y de superar los límites al encadenamiento de contratos temporales (infra 3).

Entre estos contratos presenta una especial relevancia el contrato de interinidad por vacante. Se trata de un contrato que se utiliza tanto durante los procesos de selección como durante todo el proceso de provisión y cobertura de la vacante, incluso aunque este se retrase (STS 4. ${ }^{\mathrm{a}}$, de 24 de junio de 1996, núm. rec. ud. 2954/1995; STS 4. a, de 17 de diciembre de 1997, núm. rec. ud. 4203/1996). Debe advertirse, por una parte, que su utilización con carácter fraudulento o con abuso de derecho convierte al empleado en cuestión en indefinido no fijo (infra 1.1.2) y, por otra parte, que, si bien su extinción por cobertura de plaza no da lugar a indemnización alguna (STS 4. ${ }^{\mathrm{a}}$, de 17 de diciembre de 2019, núm. rec. ud. 1758/2018), la extinción por amortización da lugar a la indemnización correspondiente al despido objetivo ex artículo 52.c) del TRLET (STS 4. ${ }^{\mathrm{a}}$, de 24 de junio de 2014, núm. rec. 217/2013).

\section{b) El personal indefinido no fijo}

De construcción jurisprudencial, podría pensarse que, actualmente, encuentra apoyo legal en los artículos 8.2.c) y 11.1 del TREBEP. En efecto, mientras que el artículo 8.2.c) establece que el personal laboral puede ser fijo, por tiempo indefinido o temporal, el artículo 11.1 señala que, en función de la duración del contrato este podrá ser fijo, por tiempo indefinido o temporal. No obstante, como ha precisado la jurisprudencia, en dichos preceptos el término "indefinido" no se refiere a los trabajadores indefinidos no fijos. En concreto, la STS $4 .^{a}$ de 22 de julio de 2013 (núm. rec. ud.1380/2012) matiza que:

La referencia que no se contenía ni en el proyecto remitido por el Gobierno a las Cortes (BOCG/CD de 27 de septiembre de 2006), ni en el que el Congreso remitió al Senado (BOCG/S, 20.1.2007), se incorporó durante la tramitación en este, como consecuencia de las enmiendas 33 y 36 del grupo de senadores nacionalistas vascos, en las que, junto al personal laboral fijo y al temporal, se añadía el indefinido, con la finalidad de que "también el profesorado de religión esté contemplado en este artículo" (BOCG/S 21.2.2007). La razón última de la inclusión está en que estos profesores, según su regulación específica (...), no son temporales, pero tampoco fijos, ya que la propuesta de la jerarquía eclesiástica excluye la aplicación de los procedimientos de selección del artículo 61 del Estatuto Básico del Empleado Público. 
Por ello, para la definición y alcance de los trabajadores indefinidos no fijos debe estarse a lo establecido por la jurisprudencia.

En realidad, se trata de una solución imaginativa que supera las dos alternativas previstas inicialmente, como consecuencia de la dificultad para aplicar la presunción de contrato indefinido que rige en el Derecho del Trabajo, para con los contratos temporales celebrados en fraude de ley, cuando el empresario es una Administración pública. Así, conforme a la primera alternativa, se entendía que las Administraciones públicas estaban sujetas al ordenamiento laboral cuando actuaban como empresario, por lo que el contrato fraudulento se convertía en indefinido. Por el contrario, la segunda alternativa consideraba que debía aplicarse preferentemente el ordenamiento jurídico administrativo, de modo que no era posible consolidar una plaza en el empleo público al margen de los procesos de selección reglados, por lo que la normativa laboral no desplegaba sus efectos en estos supuestos (Fondevila Antolín, 2018: 28-29).

En efecto, con la creación de la figura de los trabajadores indefinidos no fijos, el Tribunal Supremo pretende superar un problema aparentemente insoluble: el de la adecuada sanción de los abusos cometidos por las Administraciones públicas en la contratación temporal laboral respetando al mismo tiempo las garantías constitucionales de igualdad, publicidad, mérito y capacidad en el acceso al empleo público (Desdentado Bonete, 2018: 2).

Concretamente, la creación de la figura se produce por la STS $4 .^{a}$ de 7 de octubre de 1996 (núm. rec. ud. 3307/1995). Esta sentencia no discute la calificación de la modalidad del contrato de trabajo según su duración, sino que introduce una precisión de calado en relación con la calificación de la posición subjetiva del trabajador en la Administración pública, al establecer que:

La contratación laboral en la Administración pública al margen de un sistema adecuado de ponderación de mérito y capacidad impide equiparar a los demandantes a trabajadores fijos de plantilla, condición ligada a la contratación por el procedimiento reglamentario, sin perjuicio de su consideración, en su caso, como trabajadores vinculados por un contrato de trabajo por tiempo indefinido. (F.D. 2. ${ }^{\circ}$ )

Pese a que la STS $4 .^{\text {a }}$, de 28 de marzo de 2017 (núm. rec. ud. 1664/2015) afirme expresamente que «la figura jurídica del contrato indefinido no fijo es diferente del contrato temporal y del fijo» (F.D. 3. ${ }^{\circ}$ ), tal afirmación debe entenderse a los meros efectos de equiparar la indemnización que corresponde a los indefinidos no fijos por cobertura reglamentaria de la plaza ocupada con la que corresponde en los supuestos de despido objetivo ex artículos 52 y 53 del TRLET, de veinte días por ańo de servicio, con límite de doce mensualidades, y evitar así su equiparación con los supuestos de terminación de los contratos temporales, en los que la indemnización que se reconoce ex artículo 49.1.c) del TRLET resulta inferior, a saber, la equivalente a la parte proporcional de la 
cantidad que resulte de abonar doce días de salario por cada año de servicio. En este sentido, pudieron pesar también las dudas en torno a la perdurabilidad de la doctrina sentada por la STJUE de 14 de septiembre de 2016, Ana de Diego Porras y Ministerio de Defensa (Diego Porras I) (Asunto C-596/14), a pesar de su temprana aplicación en España a partir de la STSJ de Madrid 4. ${ }^{a}$, de 5 de octubre de 2016 (núm. rec. 246/2014) en el ámbito de las Administraciones públicas, e incluso también el ámbito de empresas privadas, a raíz de las SSTSJ del País Vasco 4.a de 18 de octubre de 2016 (núms. rec. 1690/2016 y 1872/2016), de 15 de noviembre de 2016 (núm. rec. 1990/2016) y de 22 de noviembre de 2016 (núm. rec. 2146/2016).

Esas dudas comenzaron a ser patentes, por lo menos, en el ámbito de las empresas privadas, al entender parte de la jurisprudencia, por cierto, con acertado criterio, que en ese ámbito la antes aludida STJUE no tiene efecto directo [STS] de Andalucía/Málaga 4.a de 16 de noviembre de 2016 (núm. rec. 1539/2016)]. Se considera acertada esta última jurisprudencia porque el contenido de la STJUE se refiere a una interpretación sobre la Directiva 1999/70/CE del Consejo de 28 de junio de 1999 (DOCE de 10 de julio de 1999, L 175), respecto a la cual solo es predicable su aplicación directa horizontal a propósito de una manifestación del derecho a la no discriminación: la edad (Méndez Sebastián, 2017: 171). También, respecto a los contratos formativos la jurisprudencia negó la posibilidad de aplicar los efectos de la mencionada STJUE, al considerar que la doctrina que esta sienta respecto a los contratos de interinidad no es exportable a los trabajadores con contratos formativos, ya que en el caso de estos trabajadores no hay trabajador fijo comparable [STSJ del País Vasco 4. ${ }^{\mathrm{a}}$, de 14 de marzo de 2017 (núm. rec. 458/2017)]. Incluso desde la doctrina científica se alegó la existencia de razones objetivas en la diferencia de trato contenida en la regla indemnizatoria entre los contratos interinos y formativos y el resto, al entender que en estos se da una causalidad significativa, pues la temporalidad no trae causa de la actividad empresarial, sino que, más bien, de criterios de oportunidad, propios de las políticas de empleo (Méndez Sebastián, 2017: 182 y 197).

Finalmente, a raíz de la STJUE de 5 de junio de 2018, Lucía Montero Mateos y Agencia Madrileña de Atención Social de la Consejería de Políticas Sociales y Familia de la Comunidad Autónoma de Madrid (Asunto C-677/16), se disipó cualquier duda, en el sentido de que esta sentencia declara lícito no prever el abono de indemnización alguna a los trabajadores con contratos de duración determinada celebrados para cubrir temporalmente un puesto de trabajo durante el proceso de selección o promoción para la cobertura definitiva del mencionado puesto, como el contrato de interinidad, al vencer el término por el que estos contratos se celebraron, mientras que se concede indemnización a los trabajadores fijos con motivo de la extinción de su contrato de trabajo por una causa objetiva. Esa doctrina se consolida, además, en la STJUE de 21 de noviembre de 2018, Ministerio de Defensa y Ana de Diego Porras (Diego 
Porras II), (Asunto C-619/17). Asimismo, la STS 4. a, de 9 de enero de 2019 (núm. rec. 108/2018) ha acogido dicha doctrina, al establecer que la cuantía de la indemnización puede ser distinta según cuál es la causa de la terminación de la relación laboral.

En cualquier caso, no cabe olvidar que el estatuto profesional de los indefinidos no fijos se caracteriza porque, al no haber sido contratados a través de los procedimientos reglados de selección, su vínculo está limitado por la cobertura regular del puesto que desempeñan transitoriamente, sea este hecho futuro una condición [tal y como se entendió por la STS 4. ${ }^{\mathrm{a}}$, de 27 de mayo de 2002 (núm. rec. ud. 2591/2001)] o un término [tal y como se entendió por la STS 4.a de 24 de junio de 2014, (núm. rec. 217/2013)] (Desdentado Bonete, 2018: 14).

De ahí que la STS 4. a , de 2 de abril de 2018 (núm. rec. 27/2017), vuelve a reconocer el carácter temporal de los indefinidos no fijos, al aclarar que la equiparación entre indefinidos no fijos y temporales resulta perfectamente explicable desde la perspectiva del Derecho de la Unión Europea. En ese sentido, se establece que:

La Directiva 1999/70, sobre empleos de duración determinada, garantiza la no discriminación entre los trabajadores de duración determinada y los fijos comparables, entendiendo por los primeros aquellos cuya vinculación profesional incorpora una finalización determinada por condiciones objetivas (fecha, realización obra o servicio, hecho o acontecimiento). La equiparación de derechos se edifica desde la dicotomía conceptual apuntada; desde tal perspectiva se comprende que a quienes son indefinidos no fijos se les considere como temporales, puesto que de ese modo se permite el contraste (con quien sea comparable) y queda garantizada la equiparación de derechos.

Cuestión distinta es que a los efectos de resolver la cuestión objeto de litigio, que versa sobre el reconocimiento a los interinos no fijos del derecho de promoción interna en igualdad de condiciones que el personal fijo, se pretenda matizar la particularidad de los indefinidos no fijos respecto al resto de temporales, y, en especial respecto a los interinos por vacante. Esto queda patente al señalar la sentencia lo siguiente en su F.D. $3 .^{\circ}$ :

La figura del indefinido no fijo tiende a alejarse de la interinidad por vacante y a aproximarse hacia la del trabajo fijo, sin perjuicio de que la plaza que ocupe (al margen del reflejo que ello posea en la RPT) deba ser objeto de amortización (previo cumplimiento de los trámites del despido objetivo o colectivo) o de convocatoria (abocando, en su caso, a la extinción indemnizada del contrato).

En último término, la lógica de la sentencia parece ir en el sentido de considerar que los indefinidos no fijos, aun siendo temporales, «en realidad están más 
cerca de los fijos que de los temporales en sentido propio, pues su estabilidad relativa es mayor» (Desdentado Bonete, 2018: 26). Es decir, se parte del reconocimiento de su carácter temporal, dentro del género en el que se encuadra, aunque fijando sus propias particularidades.

No en vano, se cita expresamente el Auto del TJUE de 11 de diciembre de 2014, Marta León y Ayuntamiento de Huétor Vega (Asunto C-86/14). Cabe recordar que en el apartado 41 de dicho auto se declara que los indefinidos no fijos están claramente incluidos en el ámbito de aplicación del Acuerdo Marco sobre el trabajo de duración determinada que incorpora la Directiva 1999/70/ CE. Además, se matiza que "carece de importancia a este respecto que el contrato de trabajo se denomine tras su conversión "contrato indefinido no fijo", dado que (...) tal conversión es una sanción por el recurso abusivo a sucesivos contratos de trabajo de duración determinada y no modifica la propia naturaleza de estos contratos». Cuestión distinta es que, en realidad, dicha conversión, no pueda ser considerada una sanción, porque prolonga en el tiempo una situación que nunca debió producirse, al mantener como empleado público a una persona que no cumple con los principios constitucionales de igualdad, mérito y capacidad; legaliza una contratación en origen fraudulenta; atenta contra del interés general; y no tiene en cuenta que habrá que echar mano de recursos públicos para hacer frente al pago de la indemnización correspondiente, en caso de amortización (Arufe Varela, 2015: 104).

Hay que tener en cuenta que a partir de la STS 4.a, de 24 de junio de 2014, núm. rec. 217/2013, en los supuestos de amortización, al igual que sucede en los contratos de interinidad por vacante, se abona la indemnización correspondiente al despido objetivo, ex artículo 52.c) del TRLET, incluso en las extinciones anteriores a la reforma de 2012 (STS 4. a, de 29 de octubre de 2014, núm. rec. ud. 1765/2013), a pesar de las opiniones en contra de la doctrina científica (Beltrán de Heredia Ruiz, 2012, 3-5). Por su parte, en los supuestos de cobertura de plaza procede la indemnización correspondiente a la extinción de los contratos temporales ex artículo 49.1.c) del TRLET (STS 4. a, de 6 de octubre de 2015, núm. rec. ud. 2592/2014).

En todo caso, se adquiere la condición de indefinido no fijo por resolución judicial como consecuencia de la reclamación de aquellos empleados púbicos que se encuentran en distintas situaciones que dan lugar a dicha condición según la jurisprudencia.

Entre los supuestos que dan lugar al reconocimiento de personal laboral indefinido no fijo de plantilla se encuentran el encadenamiento de contratos temporales ex artículo 15.5 del TRLET (STS de 3 de diciembre de 2013, núm. rec. ud. 816/2013); la superación del plazo previsto para la convocatoria de oferta de empleo en contratos laborales interinos por vacante, siempre que el retraso en la cobertura de plazas constituya fraude de ley o abuso de derecho (STS 4. ${ }^{a}$ de 5 de 
febrero de 2020, núm. rec. ud. 2246/2018 y STS 4. a de 6 de febrero de 2020, núm. rec. ud. 2726/2018, para supuestos en los que no se aprecia fraude de ley o abuso de derecho y, por ende, no se reconoce la condición de trabajador indefinido no fijo; STS 4. a, de 24 de abril de 2019, núm. rec. ud. 1001/2017, para supuestos en los que sí se aprecia fraude de ley o abuso de derecho y, por ende, sí se reconoce la condición de trabajador indefinido no fijo); la utilización de modalidades de contratos laborales en fraude de ley tal y como se contempla en el artículo 15.3 del TRLET (STS de 19 de marzo de 2002, núm. rec. ud. 1251/2001); y la prolongación del contrato de obra para obra y servicio determinado durante más de 3 años, como se establece en el artículo 15.1 del TRLET (Selma Penalva, 2018: 297).

\section{c) Los funcionarios interinos}

Según el apartado 1 del artículo 10 del TRLEBEP, son funcionarios interinos los que, por razones expresamente justificadas de necesidad y urgencia, son nombrados como tales para el desempeño de funciones propias de funcionarios de carrera, cuando se dé alguna de las siguientes circunstancias:

a) La existencia de plazas vacantes cuando no sea posible su cobertura por funcionarios de carrera.

b) La sustitución transitoria de los titulares.

c) La ejecución de programas de carácter temporal, que no podrán tener una duración superior a tres años, ampliable hasta doce meses más por las leyes de Función Pública.

d) El exceso o acumulación de tareas por plazo máximo de seis meses, dentro de un periodo de doce meses.

Por su parte, el apartado 2 de dicho precepto precisa que la selección de funcionarios interinos habrá de realizarse mediante procedimientos ágiles que respetarán en todo caso los principios de igualdad, mérito, capacidad y publicidad. Lo que sucede es que en la práctica es frecuente seleccionar al personal interino mediante la formación de listas de reserva o bolsas de empleo temporal constituidas por quienes no aprobaron los últimos procesos selectivos, en orden descendente de puntuación (Desdentado Daroca, 2016: 36).

Respecto al cese de estos funcionarios, al apartado 3 del mismo precepto establece que se producirá, además de por las causas generales de extinción de la relación de servicio de los funcionarios de carrera, cuando finalice la causa que dio lugar al nombramiento. En esa línea, se dispone que cuando el funcionario interino sea nombrado para ocupar una vacante, dicha vacante deberá incluirse en la oferta de empleo correspondiente al ejercicio en que se produce su nombramiento y, si no fuera posible, en la siguiente, salvo que se decida su amortización. 
A pesar de todo ello, la figura del funcionario interino se ha utilizado de manera abusiva en algunas Administraciones públicas. Así, a veces, este tipo de personal mantiene su relación de servicio con la Administración durante largos períodos de tiempo, muchas veces porque la Administración no convoca o tarda en convocar los procesos de selección correspondientes para poder cubrir la vacante con funcionarios de carrera (Desdentado Daroca, 2016: 37).

Igualmente, no debieran admitirse procesos restringidos diseñados «a la carta» para que esta clase de personal consolide su situación, pues ello viola el derecho del resto de ciudadanos al acceso al empleo público, al limitar de forma ilegal sus posibilidades. Lo mismo sería extensible al personal indefinido no fijo con más motivo, ya que este personal accede a la Administración de forma ilegal (Fondevila Antolín, 2018: 74)

Ese es el motivo por el que la STS 3. a, de 16 de septiembre de 2018 (núm. rec. 1305/2017) ha procedido a reconocer que los funcionarios interinos que padecen una situación de abuso por el incumplimiento de las medidas contemplas en el artículo 10 del TRLEBEP, si bien no se convierten en personal indefinido no fijo, subsisten y continúan con su relación de empleo de funcionario interino, con los derechos profesionales y económicos inherentes a ella hasta que la Administración cumpla en debida forma lo que establece con carácter básico el artículo 10.1 del TRLEBEP. De este modo, en la práctica, resulta extrapolable a esta situación lo ya indicado respecto a los indefinidos no fijos, en el sentido crítico de que se prolonga una situación fraudulenta. Además, al reconocerse también el derecho a indemnización, se vuelve a incurrir en un gasto para la Administración pública.

En cualquier caso, para que acabe reconociéndose el derecho a indemnización, el Tribunal Supremo ha señalado que dicho reconocimiento:

(a) depende de las circunstancias singulares del caso; (b) debe ser hecho, si procede, en el mismo proceso en que se declara la existencia de la situación de abuso; y (c) requiere que la parte demandante deduzca tal pretensión; invoque en el momento procesal oportuno qué daños y perjuicios, y que por qué concepto o conceptos en concreto, le fueron causados; y acredite por cualquiera de los medios de prueba admitidos en Derecho, la realidad de tales dańos y/o perjuicios, de suerte que sólo podrá quedar para ejecución de sentencia la fijación o determinación del quantum de la indemnización debida.

Además, se precisa que:

El concepto o conceptos dańosos y/o perjudiciales que se invoquen deben estar ligados al menoscabo o dańo, de cualquier orden, producido por la situación de abuso, pues esta es su causa, y no a hipotéticas «equivalencias», al momento del cese e inexistentes en aquel tipo de relación de empleo, con otras relaciones laborales o de empleo público. 
Cabe concluir preguntándose hasta qué punto estas medidas constituyen sanciones efectivas y disuasorias que impidan el uso abusivo del empleo administrativo temporal (Rodríguez Escanciano, 2017: 54).

\section{d) El personal eventual}

Considerado empleado público por el artículo 8.2.d) del TRLEBEP, conforme al artículo 12.1 del TRLEBEP, el personal eventual es aquel que, en virtud de nombramiento y con carácter no permanente, sólo realiza funciones expresamente calificadas como de confianza o asesoramiento especial, siendo retribuido con cargo a los créditos presupuestarios consignados para este fin.

El apartado 3 del mismo precepto añade que su nombramiento y cese serán libres, y matiza que el cese tendrá lugar, en todo caso, cuando se produzca el de la autoridad a la que se preste la función de confianza o asesoramiento.

De todo ello se deduce su naturaleza temporal. Sin embargo, la práctica, en ciertos casos, ha evidenciado un cierto abuso de esta figura, desbordando su carácter excepcional. Por tal motivo, en los apartados 2 y 4 del artículo 12 del TRLEBEP, se recogen algunas medidas para evitar tales abusos. Por una parte, se reserva a las leyes de la Función Pública la determinación de los órganos de gobierno de las Administraciones públicas que podrán disponer de este tipo de personal, aunque el número máximo se establecerá por los respectivos órganos de gobierno. Además, con la finalidad de intensificar el control político y social, se dispone que el número de eventuales y sus condiciones retributivas serán públicos. Por otra parte, la condición de personal eventual no podrá constituir mérito para el acceso a la función pública o para la promoción interna. Es más, al igual que los funcionarios interinos, los eventuales no gozan del derecho a la inamovilidad ni del derecho a la carrera (Desdentado Daroca, 2016: 38).

En relación con lo que se acaba de señalar, si bien el ser personal eventual no es mérito para el acceso a la función pública, hubiera sido más apropiado entender que el concepto de función pública en sentido amplio comprende también al personal laboral, cumpliendo así mejor con el fin último del precepto y evitando, en consecuencia, poder considerar como mérito el haber sido personal eventual para acceder a la condición de personal laboral (Boltaina Bosch, 2011: 143-144).

\section{e) El personal estatutario temporal}

La Ley 55/2003, de 16 de diciembre, del Estatuto Marco del personal estatutario de los servicios de salud (BOE de 17 de diciembre de 2003, núm. 301), regula la relación funcionarial especial del personal estatutario de los servicios de salud que conforman el Sistema Nacional de Salud (cfr. artículo 1). Entre las distintas modalidades de personal estatutario, se regula en el artículo 9 el denominado personal estatutario temporal. 
Conforme a dicho precepto, los servicios de salud pueden nombrar personal estatutario temporal por razones de necesidad, de urgencia o para el desarrollo de programas de carácter temporal, coyuntural o extraordinario ( $c f r$. apartado 1). Acto seguido, se especifica que los nombramientos de personal estatutario temporal podrán ser de interinidad, de carácter eventual o de sustitución, y se procede a definir las características de cada uno de ellos:

a) Personal administrativo interino: El nombramiento de carácter interino debe expedirse para el desempeńo de una plaza vacante de los centros o servicios de salud, cuando sea necesario atender las correspondientes funciones. Por ello, se acordará el cese del personal estatutario interino cuando se incorpore personal fijo, por el procedimiento legal o reglamentariamente establecido, a la plaza que desempeñe, así como cuando dicha plaza resulte amortizada (cfr. apartado 2).

b) Personal estatutario eventual: El nombramiento de carácter eventual se expedirá en los siguientes supuestos (cfr. apartado 3$)$ :

b.1) Cuando se trate de la prestación de servicios determinados de naturaleza temporal, coyuntural o extraordinaria.

b.2) Cuando sea necesario para garantizar el funcionamiento permanente y continuado de los centros sanitarios.

b.3) Para la prestación de servicios complementarios de una reducción de jornada ordinaria.

En coherencia con su finalidad, debe acordarse el cese del personal estatutario eventual cuando se produzca la causa o venza el plazo que expresamente se determine en su nombramiento, así como cuando se supriman las funciones que en su día lo motivaron.

Como medida anti fraude y que evita la cultura de la temporalidad a través de la concatenación de sucesivos nombramientos de carácter temporal en las Administraciones públicas, se establece que, si se realizaran más de dos nombramientos para la prestación de los mismos servicios por un período acumulado de 12 o más meses en un período de dos años, procederá el estudio de las causas que lo motivaron, para valorar, en su caso, si procede la creación de una plaza estructural en la plantilla del centro.

c) Personal estatutario de sustitución (apartado 4): El nombramiento de sustitución se expedirá cuando resulte necesario atender las funciones de personal fijo o temporal, durante los períodos de vacaciones, permisos y demás ausencias de carácter temporal que comporten la reserva de la plaza.

En coherencia con esa finalidad, debe acordarse el cese del personal estatutario sustituto cuando se reincorpore la persona a la que sustituya, 
así como cuando esta pierda su derecho a la reincorporación a la misma plaza o función.

\subsection{El empleo temporal en las Administraciones públicas por incorporación o gestión indirecta}

Respecto a la incorporación indirecta de personal, con frecuencia, las Administraciones públicas optan por celebrar con personas físicas contratos administrativos de servicios. A priori, resultaría difícil diferenciar estos contratos administrativos del contrato de trabajo, pues la diferencia entre la dependencia jurídica que caracteriza a este último y la mera sujeción a las directrices de actividad que marca la correspondiente Administración Pública será sólo teórica y no material.

No obstante, en estos casos es preciso que la contratación administrativa se adecue a los cauces específicos que para este tipo de contratación prevé la Ley 9/2017, de 8 de noviembre, de Contratos del Sector Público, por la que se transponen al ordenamiento jurídico español las Directivas del Parlamento Europeo y del Consejo 2014/23/UE y 2014/24/UE, de 26 de febrero de 2014 (BOE de 9 de noviembre de 2017, núm. 272), tanto en lo que se refiere al expediente de contratación, como a la adecuación del objeto concreto del contrato celebrado a las previsiones normativas. Así, si el servicio contratado puede encuadrarse material y formalmente en el cauce previsto para la contratación administrativa de dicha norma, regirá plenamente la exclusión que indica el artículo 1.3 del TRLET (Selma Penalva, 2006: 3-4).

Otro tanto puede decirse respecto a los supuestos en los que las Administraciones públicas acuden a Empresas de Trabajo Temporal para hacerse con los servicios de sus trabajadores (Madrid Yagüe, 2012: 177 y ss.).

De lo contrario, es decir, de no respetarse el expediente de contratación o de no adecuarse el objeto concreto del contrato celebrado a las previsiones normativas, estaríamos ante un uso fraudulento del contrato administrativo por vulneración de los principios de igualdad, mérito y capacidad que rigen en el acceso al empleo público, ya que para su celebración no se seguirían los procesos selectivos propios de los contratos laborales, interinidades y puestos funcionariales correspondientes a los empleados públicos (Recuerda Girela y Fernández Depuech, 2013: 2).

Por ello, el problema surge cuando quienes son irregularmente contratados a través de un contrato administrativo, posteriormente, solicitan el reconocimiento de su condición como personal laboral. Pues bien, en esos casos, la consecuencia jurídica es que los afectados se convierten en trabajadores indefinidos no fijos. Dicho de otro modo, lo que en su día fue una incorporación indirecta acaba siendo una incorporación directa, por lo que también de esta forma aumenta el empleo temporal en las Administraciones públicas. 
La misma situación se producirá en los supuestos en los que las Administraciones públicas acudan a falsas contratas y se declare judicialmente la existencia de dicha falsa contrata y, en consecuencia, también la cesión ilegal de mano de obra por parte de la falsa contrata a la correspondiente Administración pública, y el trabajador afectado opte, conforme a lo establecido en el artículo 43 del TRLET, por convertirse en trabajador fijo en la Administración pública en la que venía prestando servicios, con la particularidad de que, en realidad, se convierta en un trabajador indefinido no fijo (STS $4 .^{\mathrm{a}}$, de 17 de septiembre de 2002, núm. rec. ud. 3047/2001, STS 4. a de 19 de noviembre de 2002 núm. rec. ud. 909/2002, STS de 23 de noviembre de 2016, núm. rec. $91 / 2016$ ).

Sin embargo, en el supuesto de verdaderas contratas, cuando se produzca el fenómeno de sucesión de plantilla-sucesión de empresa en los términos de la STJUE de 11 de julio de 2018, Ángel Somoza Hermo e Ilunión Seguridad S.A. contra Esabe Vigilancia, S.A. y Fondo de Garantía Salarial (Asunto C-60/2017), no tendrá lugar el fenómeno.

Lo preceptuado originariamente en la letra a) del apartado primero de la Disposición Adicional vigésimo sexta de la Ley 3/2017, de 27 de junio, de Presupuestos Generales del Estado para el año 2012 (BOE de 28 de junio de 2017, núm. 153) sirve de referencia para justificarlo. Es cierto que el contenido de dicha letra a) fue declarado inconstitucional por la STC 122/2018, de 31 de octubre, pero por defectos en la técnica legislativa. En efecto, conforme a esa letra a) las Administraciones públicas no podían incorporar como empleados públicos a los trabajadores de los contratistas de concesiones de obras o servicios públicos o de cualquier otro contrato adjudicado por las Administraciones públicas, cuando los contratos se extinguieran por su cumplimiento, por resolución, incluido el rescate, o si se adoptaba el secuestro o intervención del servicio conforme a la legislación de contratos del sector público que resultase de aplicación a los mismos.

Parece que el espíritu de dicho precepto es lógico, teniendo en cuenta que ante supuestos de sucesión de plantilla-sucesión de empresa los trabajadores de la primera concesionaria deben ser asumidos por la segunda concesionaria de la Administración pública en cuestión, en los términos de la mencionada STJUE y nunca por la propia Administración.

Por último, la reversión, según algunos autores, también conlleva el reconocimiento de trabajadores indefinidos no fijos a los afectados (Fernández Avilés, 2017: 13), aunque otros prefieran considerar a los trabajadores afectados como personal a extinguir, en la línea de lo previsto por la Ley 15/2014, de 16 de septiembre, de racionalización del Sector Púbico y otras medidas de reforma administrativa (BOE de 17 de septiembre de 2014, núm. 226), al considerar que con la reversión se produce una situación especial, de gestión 
diferenciada de plantillas, entendiendo que el personal subrogado no es propiamente en sentido formal empleado público, sino personal vinculado a un servicio concreto y en condiciones a extinguir (Alfonso Mellado, 2016: 41 y 43). Finalmente, no faltan quienes sostienen que la modalidad de indefinido no fijo no es adecuada en estos casos de reversión, porque se trata de la respuesta que la jurisprudencia dio a un supuesto de contratación temporal irregular, mientras que la reversión, que supone una transmisión de empresa, es una figura totalmente ajustada a Derecho, cuyo efecto legal no es otro que la subrogación, de forma y manera que, por una parte, los trabajadores que previamente a la reversión tuvieran un contrato temporal podrían convertirse en indefinidos, en aquellos casos en los que la actividad sea permanente y estable en la Administración, y, por otra parte, los trabajadores que previamente a la reversión tuvieran un contrato indefinido, mantendrían su situación, en los términos que se acaban de exponer para con los trabajadores temporales (López Balaguer, 2018: 8-9).

\section{Los límites al empleo temporal en las Administraciones públicas derivadas de la Directiva 1999/70/CE}

Antes que nada, debe recordarse que la definición del concepto de «trabajador con contrato de duración determinada» contenida en la Cláusula 3.1. del Acuerdo Marco que incorpora la Directiva 1999/70/CE del Consejo de 28 de junio de 1999, relativa al Acuerdo Marco de la CES, la UNICE y el CEEP sobre el trabajo de duración determinada (DOCE de 10 de julio de 1999, L 175), engloba a todos los trabajadores, sin establecer diferencias en función del carácter público o privado del empleador para el que trabajan y con independencia de la calificación de su contrato en el Derecho interno [apartado 108 de la STJUE de 19 de marzo de 2020, Domingo Sánchez Ruiz y otros contra Comunidad de Madrid (Servicio Madrileño de Salud) y Consejería de Sanidad de la Comunidad de Madrid (Asuntos acumulados C-103/18 y C-429/18); apartado 67 de la STJUE de 26 de noviembre de 2014, Raffaella Mascolo y otros contra Ministero dell'Istruzione, dell'Università e della Ricerca y Comune di Napoli (Asuntos acumulados C-22/13, C-61/13 a C-63/13 y C-418/13), así como la jurisprudencia citada en dicho apartado].

Una vez realizada dicha matización, el Acuerdo Marco, en sus Considerandos, establece los primeros límites al empleo temporal, partiendo de la idea de que «los contratos de duración indefinida son la forma más común de relación laboral, y que contribuyen a la calidad de vida de los trabajadores afectados y a mejorar su rendimiento» (6. ${ }^{\circ}$ Considerando). Así, siendo esa la regla general, a continuación, se dispone que «la utilización de contratos de trabajo de duración determinada basados en razones objetivas es una forma de evitar abusos» 
(7. ${ }^{\circ}$ Considerando). Si esto último hace referencia a las causas que dan origen a la temporalidad, la Cláusula 3, al definir qué debe entenderse por «trabajador con contrato de duración determinada", ofrece una importante pista para poder concretar dichas causas, al identificar los contratos temporales con aquellos «en los que el final del contrato de trabajo o de la relación laboral viene determinado por condiciones objetivas tales como una fecha concreta, la realización de una obra o servicio determinado o la producción de un hecho o acontecimiento determinado".

La Cláusula 1, relativa al objeto del Acuerdo Marco, señala como uno de los dos objetos previstos, «establecer un marco para evitar abusos derivados de la utilización de sucesivos contratos o relaciones laborales de duración determinada».

$\mathrm{Al}$ respecto, tradicionalmente, se ha afirmado que no cabe una interpretación flexible e in extenso de dicho objeto, con la finalidad de ampliar la protección a los trabajadores temporales cuando existe un único contrato o una única relación con su empleador [cfr. apartados 41-43 de la STJUE de 22 de noviembre de 2005, Weber Mangold contra Rüdiger Helm (Asunto C-144/04); apartado 45 de la STJUE de 26 de enero de 2012, Bianca Kücük contra Land Nordrhein-Westfalen (Asunto C-586/10); apartado 55 del ATJUE de 12 de junio de 2019, María Teresa Aragón Carrasco y otros contra Administración del Estado (Asunto C-367/18) y apartado 70 de la STJUE de 22 de enero de 2020, Almudena Baldonedo Martín contra Ayuntamiento de Madrid (Asunto C-177/18)].

Por su parte, la Cláusula 5, bajo la rúbrica «Medidas destinadas a evitar la utilización abusiva» viene a desarrollar el mencionado objeto. De este modo, para prevenir abusos en la utilización sucesiva de contratos o relaciones laborales de duración determinada, pues se ha considerado por la jurisprudencia de la Unión que dicha utilización constituye una fuente potencial de abusos en perjuicio de los trabajadores [apartado 26 de la STJUE de 14 de septiembre de 2016, María Elena Pérez López contra Servicio Madrileño de Salud (Comunidad de Madrid) (Asunto C-16/15), así como la jurisprudencia citada en dicho apartado], deben introducirse una o varias de las siguientes medidas, teniendo en cuenta las necesidades de los distintos sectores y/o categorías de trabajadores, y sin perjuicio de que puedan existir en cada Estado miembro medidas legales equivalentes:

a) Razones objetivas que justifiquen la renovación de tales contratos o relaciones laborales.

b) La duración máxima total de los sucesivos contratos o relaciones laborales de duración determinada.

c) El número de renovaciones de tales contratos o relaciones laborales. 
Además, se deja en manos de los Estados miembros, determinar «en qué condiciones los contratos de trabajo o relaciones laborales de duración determinada:

a) se considerarán "sucesivos";

b) se considerarán celebrados por tiempo indefinido".

En relación con la remisión a los Estados miembros de cara a que sean estos quienes determinen las modalidades concretas de aplicación del término «sucesivos», a efectos del Acuerdo Marco, debe matizarse, con la STJUE de 19 de marzo de 2020, Domingo Sánchez Ruiz y otros contra Comunidad de Madrid (Servicio Madrileño de Salud) y Consejería de Sanidad de la Comunidad de Madrid (Asuntos acumulados C-103/18 y C-429/18), que el margen de apreciación así atribuido no es ilimitado, ya que en ningún caso puede llegar hasta el punto de poner en peligro el objetivo o el efecto útil del Acuerdo Marco ( $c f r$. apartado 58). De ahí que no quepa una definición demasiado restrictiva del concepto, pues ello permitiría emplear a trabajadores de forma precaria durante años ( $c f r$. apartado 62). En consecuencia, no cabe excluir del concepto de «sucesivos contratos o relaciones laborales de duración determinada", a efectos de dicha Cláusula, una situación en la que un empleado público nombrado sobre la base de una relación de servicio de duración determinada, a saber, hasta que la plaza vacante para la que ha sido nombrado sea provista de forma definitiva, ha ocupado, en el marco de varios nombramientos, el mismo puesto de trabajo de modo ininterrumpido durante varios ańos y ha desempeñado de forma constante y continuada las mismas funciones, cuando el mantenimiento de modo permanente de dicho empleado público en esa plaza vacante se debe al incumplimiento por parte del empleador de su obligación legal de organizar en el plazo previsto un proceso selectivo al objeto de proveer definitivamente la mencionada plaza vacante y su relación de servicio haya sido prorrogada implícitamente de año en año por este motivo (cfr. apartado 64).

\section{Los limites al empleo temporal en las Administraciones públicas derivados de la normativa espańola}

En la normativa española son varias las normas que contienen límites al empleo temporal en las Administraciones públicas.

Comenzando por el TRLET, la Disposición Adicional decimoquinta de dicho cuerpo normativo, bajo la rúbrica «Aplicación de los límites de duración del contrato por obra o servicio determinados y al encadenamiento de contratos en las Administraciones públicas», establece una serie de matizaciones para con la 
duración máxima del contrato por obra o servicio determinados establecida en el artículo 15.1.a) y los límites al encadenamiento de contratos regulados en el artículo 15.5 del mismo cuerpo legal.

Así, si bien los mismos deben surtir efectos también en el ámbito de las Administraciones públicas y sus organismos públicos vinculados o dependientes, quedan supeditados a la aplicación de los principios constitucionales de igualdad, mérito y capacidad en el acceso al empleo público. De ahí que las consecuencias de los límites fijados en ambos preceptos no pueden obstaculizar la obligación de las Administraciones públicas de proceder a la cobertura de los puestos de trabajo de que se trate a través de los procedimientos ordinarios, de acuerdo con lo establecido en la normativa aplicable. Por ello, se prevé que, el trabajador afectado continuará desempeńando el puesto que venía ocupando hasta que se proceda a su cobertura por los procedimientos citados, momento en el que se producirá la extinción de la relación laboral, salvo que el mencionado trabajador acceda a un empleo público, superando el correspondiente proceso selectivo ( $c f r$. apartado 1). En suma, se da amparo de manera tácita la figura del trabajador indefinido no fijo para cuando se superan los límites contemplados en los artículos 15.1.a) y 15.5 del TRLET (Selma Penalva, 2018: 299 y 302).

Igualmente, se matiza que para la aplicación del límite al encadenamiento de contratos previsto en el artículo 15.5 del TRLET solo se tendrán en cuenta los contratos celebrados en el ámbito de cada una de las Administraciones públicas, sin que formen parte de ellas, a estos efectos, los organismos públicos, agencias y demás entidades de Derecho público con personalidad jurídica propia vinculadas o dependientes de las mismas (cfr. apartado 3).

Por su parte, en el ámbito del TRLEBEP, como complemento de lo preceptuado en la Disposición Adicional decimoquinta del TRLET, se prevé, en la Disposición Transitoria cuarta, bajo la rúbrica «Consolidación de empleo temporal», que las Administraciones públicas pueden efectuar convocatorias de consolidación de empleo a puestos o plazas de carácter estructural correspondientes a sus distintos cuerpos, escalas o categorías, que estén dotados presupuestariamente y se encuentren desempeñados interina o temporalmente con anterioridad a 1 de enero de 2005 ( $c$ fr. apartado 1). La sinergia respecto a la Disposición Adicional decimoquinta del TRLET vuelve a aflorar al hacerse hincapié en que los procesos selectivos garantizarán el cumplimiento de los principios de igualdad, mérito, capacidad y publicidad (cfr. apartado 2 ).

En esa misma línea, el artículo 70 dispone que las necesidades de recursos humanos, con asignación presupuestaria, que deban proveerse mediante la incorporación de personal de nuevo ingreso serán objeto de la Oferta de empleo público, o a través de otro instrumento similar de gestión de la provisión de las necesidades de personal. Para ello se establece la obligación de 
convocar los correspondientes procesos selectivos para las plazas comprometidas y hasta un $10 \%$ adicional, fijando el plazo máximo para la convocatoria de los mismos. Además, la ejecución de la oferta de empleo público o instrumento similar debe desarrollarse dentro del plazo improrrogable de 3 años (cfr. apartado 1).

Por otro lado, deben traerse a colación como verdaderos límites al empleo temporal en las Administraciones públicas, las medidas ya analizadas en materia de funcionarios interinos por vacante ex artículo 10 del TRLEBEP (supra 1.1.3) y de personal estatutario temporal ex Ley 55/2003 (supra 1.1.5).

En suma, con la importante excepción de los trabajadores indefinidos no fijos y de los efectos derivados de la STS 3.a , de 16 de septiembre de 2018 (núm. rec. 1305/2017) para con los funcionarios interinos, puede decirse que la legislación actual respeta, sin perjuicio de lo que suceda en la práctica, los límites indicados en el Informe de la Comisión para el estudio y preparación del Estatuto Básico del empleado público (Instituto Nacional de Administración Pública, 2005). Estos límites, que se recogen en dicho informe en forma de medidas, suponen que (pp. 60-61):

a) Si se trata del desempeño de plazas vacantes de plantilla, debe establecerse la necesidad de incluirlas en la primera oferta de empleo público posterior a la interinidad, salvo que se decida su amortización. Además, (...) deben fijarse plazos máximos para la provisión de las vacantes por personal fijo, transcurridos los cuales la plaza se entendería amortizada.

b) Si se trata de un nombramiento o contrato para sustituir a un empleado ausente, debe disponerse el cese del interino o contratado, en todo caso, cuando se reincorpore el funcionario o contratado fijo sustituido o este pierda el derecho a la reincorporación en el mismo puesto de trabajo.

c) Si se trata de subvenir a necesidades urgentes, extraordinarias y circunstanciales de incremento de la actividad con el nombramiento de personal temporal, este debe cesar en cuanto dichas necesidades desaparezcan y, en todo caso, en el plazo máximo que establezca la legislación laboral.

d) Si se trata de ejecutar programas temporales, debe exigirse que los mismos tengan una duración determinada y que los funcionarios o el personal laboral nombrados con tal carácter cesen necesariamente a su finalización. Más aun, debe prohibirse que se prorroguen o se reiteren programas temporales de similar contenido, sin que medie un informe previo sobre su eventual justificación o sobre si procede, por el contrario, la creación de plazas de carácter permanente y su provisión con personal fijo.

Ciertamente, el hecho de que en el mencionado informe se reconozca que "con harta frecuencia y en muchas Administraciones públicas la relación de empleo o de servicio de carácter temporal se prologa de manera irregular, al finalizar el plazo de duración del contrato o la causa que legitimó la contratación o el nombramiento del funcionario interino» (p. 61), no hace más que justificar la 
necesidad de analizar si en el ordenamiento jurídico espańol se prevén medidas alternativas para prevenir y sancionar el uso abusivo del empleo temporal en las Administraciones públicas.

\section{Las medidas alternativas para prevenir y sancionar el uso abusivo del empleo temporal en las Administraciones públicas}

La Cláusula 5 del Acuerdo Marco no establece sanciones específicas en caso de que se compruebe la existencia de abusos en la utilización sucesiva de contratos o relaciones laborales de duración determinada. En tal caso, corresponde a las autoridades nacionales adoptar medidas que no solo deben ser proporcionadas, sino también lo bastante efectivas y disuasorias como para garantizar la plena eficacia de las normas adoptadas en aplicación del Acuerdo Marco [apartado 86 de la STJUE de 19 de marzo de 2020, Domingo Sánchez Ruiz y otros contra Comunidad de Madrid (Servicio Madrileño de Salud) y Consejería de Sanidad de la Comunidad de Madrid (Asuntos acumulados C-103/18 y C-429/18); y apartado 87 de la STJUE de 21 de noviembre de 2018, Ministerio de Defensa contra Ana de Diego Porras (Diego Porras II) (Asunto C-619/17), así como la jurisprudencia citada en dicho apartado].

Asimismo, hay que tener en cuenta, que, si bien conforme a la interpretación realizada por el TJUE de dicha Cláusula, es posible que los Estados miembros establezcan sanciones para disuadir la utilización de sucesivos contratos o relaciones laborales, el mismo tribunal ha indicado que dicha Cláusula no puede fundamentar que los Estados miembros adopten sanciones cuando se haya celebrado un primer o único contrato de trabajo de duración determinada, cuando tal contrato cubre, en realidad, necesidades permanentes y duraderas del empleador [STJUE de 23 de abril de 2009, Kiriaki Angelidaki y otros contra Organismos Nomarchiakis Autodioikisis Rethymnis (C-378/07), Charikleia Giannoudi contra Dimos Geropotamou (C-379/07) y Georgios Karabousanos y Sofoklis Michopoulos contra Dimos Geropotamou (C-380/07)].

Así, a los efectos de dar cumplimiento a la Cláusula 5 del Acuerdo Marco, los Estados miembros son libres para establecer medidas adecuadas a efectos de prevenir y, en su caso, sancionar los abusos derivados de la utilización de sucesivos contratos o relaciones laborales de duración determinada.

Cuestión distinta es que los propios tribunales de un Estado miembro duden sobre la existencia en su Derecho de tales medidas, y, no solo eso, sino que también así se lo planteen, como cuestión prejudicial, al TJUE.

Es lo que, ha ocurrido en España, tal y como se recoge en la STJUE de 19 de marzo de 2020, Domingo Sánchez Ruiz y otros contra Comunidad de Ma- 
drid (Servicio Madrileño de Salud) y Consejería de Sanidad de la Comunidad de Madrid (Asuntos acumulados C-103/18 y C-429/18), cuando dicha cuestión ha sido planteada por los Juzgados de lo Contencioso-Administrativo núms. 8 y 14 de Madrid. Debe matizarse que esta sentencia, si bien se enmarca en un conflicto sobre la temporalidad del personal estatutario, sus consecuencias son extrapolables al resto de colectivos de las Administraciones públicas que padecen las consecuencias de la temporalidad cuando la misma no procede.

Sin embargo, como se verá a continuación, en España sí existen medidas adecuadas a efectos de prevenir y, en su caso, sancionar los abusos derivados de la utilización de sucesivos contratos o relaciones laborales de duración determinada. Tales medidas no solo son apreciables directamente en la normativa vigente, sino que también son deducibles de la misma, de una manera indirecta, gracias a la jurisprudencia del TJUE.

Comenzando por la normativa interna, la Ley 3/2017, de 27 de junio, de Presupuestos Generales del Estado para el año 2017 (BOE de 28 de junio de 2017, núm. 153), en su Disposición Adicional trigésimo cuarta, bajo la rúbrica, «Exigencia de responsabilidades en las Administraciones públicas y entidades dependientes de las mismas por la utilización de la contratación laboral», establece una serie de medidas que, sin duda, previenen y, en su caso, sancionan el uso indiscriminado de la contratación temporal de carácter laboral.

La primera medida preventiva consiste en recordar que en Espańa existe normativa conforme a la que deben formalizarse los contratos de trabajo del personal laboral en las Administraciones públicas y en su sector público, cualquiera que sea la duración de los mismos, siéndoles de aplicación los principios de igualdad, publicidad, mérito y capacidad en el acceso al empleo público, y debiendo respetar en todo caso lo dispuesto en la Ley 53/1984, de 26 de diciembre, de Incompatibilidades del Personal al Servicio de las Administraciones Públicas (BOE de 4 de enero de 1985, núm. 4), y cualquier otra normativa en materia de incompatibilidades ( $c f r$. apartado Uno).

La segunda medida preventiva radica en hacer responsables del cumplimiento de la citada normativa a los órganos competentes en materia de personal de cada una de las Administraciones Públicas y de las entidades que conforman su Sector Público Instrumental. Además, se prevé, expresamente, que tales órganos deben velar, en especial, para evitar cualquier tipo de irregularidad en la contratación laboral temporal que pueda dar lugar a la conversión de un contrato temporal en indefinido no fijo ( $c f r$. apartado Dos).

La tercera medida preventiva consiste en la prohibición que tienen los órganos de personal citados de atribuir la condición de indefinido no fijo a personal con un contrato de trabajo temporal, dado que ello solamente es posible que, en su caso, se reconozca por resolución judicial (cfr. apartado Dos, in fine). 
Una cuarta medida preventiva consiste en la obligación de las Administraciones públicas de promover en sus ámbitos respectivos el desarrollo de criterios de actuación que permitan asegurar el cumplimiento de todo lo anterior, así como una actuación coordinada de los distintos órganos con competencia en materia de personal ( $c f r$. apartado Cuatro). Al respecto, sigue siendo válida la recomendación realizada en el Informe de la Comisión para el estudio y preparación del Estatuto Básico del empleado público (Instituto Nacional de Administración Pública, 2005), según la cual (p. 63):

Ha de emitirse informe jurídico preceptivo, por el titular del órgano competente en cada caso, bajo su propia responsabilidad, sobre la imposibilidad legal de prorrogar de manera expresa o implícita el nombramiento de interino o contrato temporal que finaliza. Emitido dicho informe, el titular del órgano de contratación asume la responsabilidad personal de naturaleza disciplinaria, patrimonial o, en su caso, penal, que le corresponda según la legislación vigente por la prolongación irregular de la relación de servicio o laboral.

En lo que se refiere a la sanción, se establece que las actuaciones irregulares en la materia darán lugar a la exigencia de responsabilidades a los titulares de los órganos de personal mencionados, de conformidad con la normativa vigente en cada una de las Administraciones públicas ( $c f r$. apartado Tres).

Centrando la atención en la jurisprudencia del TJUE, cabe señalar distintos aspectos señalados por la misma, que los tribunales internos deben considerar en la interpretación y aplicación del Derecho interno:

a) La Cláusula 5 del Acuerdo Marco no se opone a que una norma nacional prohíba de forma absoluta, en el sector público, transformar en un contrato de trabajo por tiempo indefinido una sucesión de contratos de trabajo de duración determinada que, en realidad, tienen por objeto cubrir necesidades permanentes y duraderas del empleador. No obstante, para ello es necesario que el ordenamiento jurídico interno del Estado miembro en cuestión cuente, en dicho sector, con otra medida efectiva para evitar y, en su caso, sancionar la utilización abusiva de sucesivos contratos de trabajo de duración determinada [apartado 184 de STJUE de 23 de abril de 2009, Kiriaki Angelidaki y otros contra Organismos Nomarchiakis Autodioikisis Rethymnis (C-378/07), Charikleia Giannoudi contra Dimos Geropotamou (C-379/07) y Georgios Karabousanos y Sofoklis Michopoulos contra Dimos Geropotamou (C-380/07), (Asuntos acumulados C-378/07 a C-380/07), así como la jurisprudencia citada en dicho apartado].

b) La Cláusula 5 del Acuerdo Marco no impone a los Estados miembros una obligación general de transformar en contratos por tiempo indefinido los contratos de trabajo de duración determinada como medida 
para evitar la utilización abusiva de sucesivos contratos de trabajo de duración determinada. Ello es así porque el ordenamiento jurídico interno del Estado miembro de que se trate debe contar con otra medida efectiva para evitar y, en su caso, sancionar dicha utilización abusiva [apartado 87 de la STJUE de 19 de marzo de 2020, Domingo Sánchez Ruiz y otros contra Comunidad de Madrid (Servicio Madrileño de Salud) y Consejería de Sanidad de la Comunidad de Madrid (Asuntos acumulados C-103/18 y C-429/18), así como la jurisprudencia citada en dio apartado].

c) No se ajusta a la Cláusula 5 del Acuerdo Marco el hecho de que la normativa y jurisprudencia nacionales justifiquen que el empleador proceda a la renovación sucesiva de relaciones de servicio de duración determinada para responder a necesidades permanentes y estables en materia de personal, con fundamento en que tales renovaciones se llevan a cabo ajustándose a las causas de nombramiento previstas por la normativa interna, sin que, por el contrario, impidan ese modo de actuar [apartado 80 de la STJUE de 19 de marzo de 2020, Domingo Sánchez Ruiz y otros contra Comunidad de Madrid (Servicio Madrileño de Salud) y Consejería de Sanidad de la Comunidad de Madrid (Asuntos acumulados C-103/18 y C-429/18)]. Ciertamente, como recuerda la STJUE de 14 de septiembre de 2016, María Elena Pérez López contra Servicio Madrileño de Salud (Comunidad de Madrid) (Asunto C-16/15), es admisible que una normativa nacional permita la renovación de sucesivos contratos de trabajo de duración determinada para sustituir personal a la espera de que se creen puestos estructurales, siempre que ello esté justificado por una razón objetiva acorde con la Cláusula 5 del Acuerdo Marco (cfr. apartado 54). Pero ello no es óbice para que los tribunales procedan a averiguar la licitud de la razón objetiva que permite dichas renovaciones, con el objetivo de cerciorarse de que, en realidad, no se están encubriendo, mediante contrataciones temporales, situaciones objetivas que justifiquen una obligada creación de plantilla fija (Fondevila Antolín, 2018: 47).

d) Debe considerarse una medida legal equivalente a las categorías de medidas contempladas en la Cláusula 5.1, letras a) a c), para prevenir la utilización abusiva de sucesivos contratos o relaciones laborales de duración determinada, la organización, dentro de los plazos exigidos, de procesos selectivos que tengan por objeto la provisión definitiva de las plazas ocupadas provisionalmente por empleados públicos con una relación de servicio de duración determinada. Debe entenderse que esta medida es adecuada para evitar que se perpetúe la situación de precariedad de dichos empleados, al garantizar que las plazas que ocupan se cubran rápidamente de manera definitiva [apartado 94 de la STJUE de 19 de marzo de 2020, Domingo Sánchez Ruiz y otros contra Comunidad 
de Madrid (Servicio Madrileño de Salud) y Consejería de Sanidad de la Comunidad de Madrid (Asuntos acumulados C-103/18 y C-429/18)].

Ahora bien, debe garantizarse que esos procesos tienen que organizarse efectivamente, porque, de lo contrario, la medida no resultaría adecuada, es decir, suficientemente efectiva y disuasoria para garantizar la plena eficacia de las normas adoptadas en aplicación del Acuerdo Marco. Además, en este último supuesto, debe sancionarse dicha actuación, creando un efecto negativo en el empleador [apartado 97 de la STJUE de 19 de marzo de 2020, Domingo Sánchez Ruiz y otros contra Comunidad de Madrid (Servicio Madrileño de Salud) y Consejería de Sanidad de la Comunidad de Madrid (Asuntos acumulados C-103/18 y C-429/18)].

En todo caso, lo que no se consigue con la organización de estos procesos selectivos es la reparación de los empleados que hayan podido sufrir el abuso. Con otras palabras, la mera oportunidad de intentar acceder a la estabilidad en el empleo a través de la participación en dichos procesos no es suficiente porque tales procesos presentan un resultado incierto y también están abiertos a los candidatos que no han sido víctimas del abuso. Ciertamente, la organización de tales procesos es independiente de cualquier consideración relativa al carácter abusivo de la utilización de relaciones de servicio de duración determinada [apartados 100 y 101 de la STJUE de 19 de marzo de 2020, Domingo Sánchez Ruiz y otros contra Comunidad de Madrid (Servicio Madrileño de Salud) y Consejería de Sanidad de la Comunidad de Madrid (Asuntos acumulados C-103/18 y C-429/18)].

Pero todo ello debe ser apreciado por los tribunales internos, con arreglo al conjunto de normas de su Derecho nacional aplicables, a fin de valorar si la organización de procesos selectivos destinados a proveer definitivamente las plazas ocupadas con carácter provisional por empleados públicos nombrados en el marco de relaciones de servicio de duración determinada puede considerarse una medida adecuada prevenir y, en su caso, sancionar los abusos derivados de la utilización de sucesivos contratos o relaciones laborales de duración determinada [apartado 106 de la STJUE de 19 de marzo de 2020, Domingo Sánchez Ruiz y otros contra Comunidad de Madrid (Servicio Madrileño de Salud) y Consejería de Sanidad de la Comunidad de Madrid (Asuntos acumulados C-103/18 y C-429/18)].

e) La transformación de los empleados públicos que hayan sido nombrados de manera abusiva en el marco de sucesivas relaciones de servicio de duración determinada en indefinidos no fijos no permite por sí sola alcanzar la finalidad perseguida por la Cláusula 5 del Acuerdo Marco porque dicha transformación se produce sin perjuicio de la posibilidad de que el empleador amortice la plaza o cese al empleado público 
con nombramiento de duración determinada de que se trate cuando la plaza se cubra por reingreso del funcionario sustituido. Además, hay que tener en cuenta que, a diferencia de la transformación, en el sector privado, de los sucesivos contratos de trabajo de duración determinada en contratos de trabajo por tiempo indefinido, la transformación de los empleados públicos con nombramiento de duración determinada en indefinidos no fijos no les permite disfrutar de las mismas condiciones de trabajo que el personal estatutario fijo [apartado 102 de la STJUE de 19 de marzo de 2020, Domingo Sánchez Ruiz y otros contra Comunidad de Madrid (Servicio Madrileńo de Salud) y Consejería de Sanidad de la Comunidad de Madrid (Asuntos acumulados C-103/18 y C-429/18)].

De todos modos, nuevamente, todo ello debe ser apreciado por los tribunales internos, con arreglo al conjunto de normas de su Derecho nacional aplicables, a fin de valorar si la transformación en indefinidos no fijos puede considerarse una medida adecuada para para prevenir $\mathrm{y}$, en su caso, sancionar los abusos derivados de la utilización de sucesivos contratos o relaciones laborales de duración determinada [apartado 106 de la STJUE de 19 de marzo de 2020, Domingo Sánchez Ruiz y otros contra Comunidad de Madrid (Servicio Madrileño de Salud) y Consejería de Sanidad de la Comunidad de Madrid (Asuntos acumulados C-103/18 y C-429/18)].

f) La concesión de una indemnización equivalente a la abonada en caso de despido improcedente puede consistir en una medida legal equivalente en los términos de la Cláusula 5 del Acuerdo Marco, siempre y cuando dicha concesión tenga por objeto compensar los efectos de la utilización abusiva de sucesivos contratos o relaciones laborales de duración determinada. Además, dicha indemnización no solo debe ser proporcionada, sino también lo bastante efectiva y disuasoria como para garantizar la plena eficacia de la Cláusula 5 del Acuerdo Marco. En cualquier caso, corresponde a los tribunales internos determinar si la indemnización en cuestión constituye una medida adecuada para prevenir y, en su caso, sancionar el abuso, con arreglo al conjunto de normas de su Derecho nacional aplicable [apartados 103, 104, 105 y 106 de la STJUE de 19 de marzo de 2020, Domingo Sánchez Ruiz y otros contra Comunidad de Madrid (Servicio Madrileño de Salud) y Consejería de Sanidad de la Comunidad de Madrid (Asuntos acumulados C-103/18 y C-429/18); apartados 94 y 95y de la STJUE de 21 de noviembre de 2018, Ministerio de Defensa contra Ana de Diego Porras (Diego Porras II) (Asunto C-619/17), aunque en esta última sentencia la indemnización valorada fuera la contemplada en el artículo 49.1 del TRLET].

g) La Cláusula 5 del Acuerdo Marco debe interpretarse en el sentido de que, en caso de utilización abusiva por parte de un empleador público 
de sucesivas relaciones de servicio de duración determinada, el hecho de que el empleado público de que se trate haya consentido el establecimiento o la renovación de dichas relaciones no priva, desde ese punto de vista, de carácter abusivo al comportamiento del empleador de modo que el Acuerdo Marco no sea aplicable a la situación de ese empleado público [apartado 116 de la STJUE de 19 de marzo de 2020, Domingo Sánchez Ruiz y otros contra Comunidad de Madrid (Servicio Madrileño de Salud) y Consejería de Sanidad de la Comunidad de Madrid (Asuntos acumulados C-103/18 y C-429/18)].

h) La Cláusula 5 del Acuerdo Marco carece de efecto directo, porque no es incondicional ni suficientemente precisa, y, por ende, no puede invocarse como tal por un particular ante un juez nacional con el fin de excluir la aplicación de una disposición de Derecho nacional que le sea contraria. De ahí que un tribunal nacional no esté obligado a dejar sin aplicación una disposición de su Derecho nacional contraria a la Cláusula 5 del Acuerdo Marco. Ello no obstante, los tribunales internos, tomando en consideración la totalidad de su Derecho interno y aplicando los métodos de interpretación reconocidos por este, deben hacer todo lo que sea de su competencia a fin de garantizar la plena efectividad del Acuerdo Marco y alcanzar una solución conforme con el objetivo perseguido por esta [apartados 118 a 125 de la STJUE de 19 de marzo de 2020, Domingo Sánchez Ruiz y otros contra Comunidad de Madrid (Servicio Madrileño de Salud) y Consejería de Sanidad de la Comunidad de Madrid (Asuntos acumulados C-103/18 y C-429/18), así como la jurisprudencia citada en dichos apartados].

\section{Conclusiones}

Primera. El empleo temporal en las Administraciones públicas continúa siendo demasiado elevado. Para tratar ese problema, previamente, es necesario diferenciar las distintas modalidades de empleo temporal que pueden existir en las Administraciones públicas. A tal efecto, resulta esencial considerar no solamente el personal incorporado de manera directa, sino que también el personal que se incorpora de manera indirecta.

Segunda. Entre las modalidades de empleo que suponen una incorporación directa, las que más problemas suponen para que la temporalidad disminuya son el empleo del personal laboral de interinidad por vacante y el empleo de los indefinidos no fijos.

Así, el hecho de que la utilización, con carácter fraudulento o con abuso de derecho, del contrato de interinidad por vacante suponga la conversión del em- 
pleado que la padece en indefinido no fijo, no hace más que prolongar una situación de temporalidad que nunca debió producirse más allá de lo legalmente previsto.

Por su parte, los empleados indefinidos no fijos, que siguen constituyendo una modalidad de empleo temporal, pese a que nunca debieron existir por incumplir los procesos de selección reglados y vulnerar, en consecuencia, los principios de igualdad, mérito y capacidad, prolongan en el tiempo situaciones en origen fraudulentas, atentando contra el interés general y, en su caso, ante su eventual amortización, generando un coste a la Administración que equivale a la indemnización por despido objetivo.

Además, el problema que plantea la figura del indefinido no fijo es que la jurisprudencia, durante años, ha ido ampliando las situaciones que dan lugar a la misma.

Al margen de estas dos modalidades de empleo temporal, resulta preocupante la jurisprudencia sentada respecto a los funcionarios interinos por la STS 3. a, de 16 de septiembre de 2018 (núm. rec. 1305/2017), que, si bien pretende hacer frente a las situaciones abusivas que estos pueden padecer, en realidad, prolonga una situación fraudulenta y genera costes por las indemnizaciones que reconoce pudieran tener lugar.

Tercera. La incorporación indirecta de personal temporal a las Administraciones públicas se produce, principalmente, en supuestos de contratos administrativos de servicios celebrados con personas físicas y con personas jurídicas vía contratas o empresas de trabajo temporal. Además, en los supuestos en los que se produzca un fraude de ley en la contratación, los afectados se convertirán, previa resolución judicial, en indefinidos no fijos y, por ende, pasarán a formar parte de la planilla de la Administración pública en cuestión. Es lo que sucede con los falsos contratos administrativos que encubren contratos laborales y con la cesión ilegal de trabajadores, existiendo dudas respecto al fenómeno de la reversión.

Cuarta. La Directiva 1999/70/CE se aplica también a los empleados públicos. De la misma derivan una serie de límites al empleo temporal. Así, dichos límites se refieren, en primer lugar, a que los contratos temporales deben obedecer a razones objetivas, como el hecho de que el final del contrato de trabajo o de la relación laboral responda al cumplimiento de una fecha concreta, a la realización de una obra o servicio determinado, o a la producción de un hecho o acontecimiento determinado. En segundo lugar, deben evitarse los abusos derivados de la utilización de sucesivos contratos o relaciones laborales de duración determinada y para ello los Estados miembros deben introducir alguna o algunas de las medidas previstas en la propia Directiva o implementar sus propias medidas legales equivalentes. 
Quinta. En la normativa española son varias las normas que contienen límites al empleo temporal en las Administraciones públicas.

Por una parte, respecto al personal laboral debe estarse a lo dispuesto por la Disposición Adicional decimoquinta del TRLET. Así, cuando se superan los límites contemplados en los artículos 15.1.a) y 15.5 del TRLET, el empleado afectado continuará desempeñando el puesto que venía ocupando hasta que se proceda a su cobertura. Todo ello debe completarse con lo establecido en la Disposición Transitoria cuarta del TRLEBEP, ya que prevé que las Administraciones públicas pueden efectuar convocatorias de consolidación de empleo.

Por su parte, el artículo 70 del TRLEBEP incorpora una serie de garantías para que las necesidades de recursos humanos en las Administraciones públicas se cubran adecuadamente, a través de las correspondientes ofertas de empleo público o instrumentos similares.

Asimismo, también se contemplan límites al empleo temporal en las Administraciones públicas en la regulación de los funcionarios interinos por vacante en el artículo 10 del TRLEBEP y del personal estatutario temporal en la Ley 55/2003.

Sin embargo, la figura de los indefinidos no fijos y los efectos derivados de la STS 3. a, de 16 de septiembre de 2018 (núm. rec. 1305/2017), para con los funcionarios interinos constituyen dos excepciones demasiado importantes que ponen en peligro la virtualidad de los límites a la temporalidad en las Administraciones públicas.

Sexta. Ante la existencia de abusos en la utilización sucesiva de contratos o relaciones laborales de duración determinada, los Estados miembros son libres para establecer medidas adecuadas a efectos de prevenir y, en su caso, sancionar los abusos derivados de la utilización de sucesivos contratos o relaciones laborales de duración determinada. En concreto, en España, existen tales medidas, bien recogidas directamente en la normativa vigente, bien en aplicación de la jurisprudencia emanada sobre esta materia del TJUE.

Séptima. La Disposición Adicional trigésimo cuarta de la Ley 3/2017, de 27 de junio, de Presupuestos Generales del Estado para el año 2017 establece una serie de medidas que, sin duda, previenen y, en su caso, sancionan el uso indiscriminado de la contratación temporal de carácter laboral. Entre tales medidas debe destacarse que se hace responsable del cumplimiento de la normativa en materia de contratos de trabajo del personal laboral a los órganos competentes en materia de personal de cada una de las Administraciones Públicas y de las entidades que conforman su Sector Público Instrumental. Además, estos órganos deben evitar cualquier tipo de irregularidad en la contratación laboral temporal que pueda dar lugar a la conversión de un contrato temporal en indefinido no fijo. Para el cumplimiento de todo ello, las Administraciones públicas deben 
fijar criterios de actuación. Al respecto, se considera oportuno seguir la recomendación recogida en el Informe de la Comisión para el estudio y preparación del Estatuto Básico del empleado público.

Pero incluso más allá de las medidas preventivas, el ordenamiento jurídico español contempla una importante sanción que disuade el abuso en la contratación temporal. Se trata de exigir responsabilidades a los titulares de los órganos de personal mencionados.

El problema que presenta la Disposición Adicional trigésimo cuarta de la Ley 3/2017 es que se ciñe solo al personal laboral y no alcanza, por tanto, a los funcionarios interinos y al personal estatutario temporal. Ciertamente, una respuesta unitaria sería aconsejable, para que, partiendo de la responsabilidad patrimonial de la Administración, por una parte, se abonara la indemnización correspondiente al empleado afectado por el funcionamiento anormal de la Administración, y, por otra parte, se ejercitara la acción de regreso contra los titulares de los órganos de contratación correspondientes, sin perjuicio de las responsabilidades disciplinarias o penales en las que estos también pudieran incurrir.

Octava. En aplicación de la jurisprudencia emanada del TJUE sobre las medidas que previenen y, en su caso, sancionan los abusos derivados de la utilización de sucesivos contratos o relaciones laborales de duración determinada, deben considerarse los siguientes aspectos:

a) En las Administraciones públicas españolas existe la prohibición absoluta de transformar contratos temporales en fijos, y ello resulta conforme a la Cláusula 5 del Acuerdo Marco de la Directiva 1999/70/CE, porque en el ordenamiento jurídico español se recogen medidas que limitan la contratación temporal y medidas que previenen y sancionan la concatenación de distintos contratos temporales. Igualmente, como consecuencia de que existen tales medidas, en España no existe la obligación general de transformar en contratos por tiempo indefinido los contratos de trabajo de duración determinada como medida para evitar la utilización abusiva de sucesivos contratos de trabajo de duración determinada.

b) No procede la renovación sucesiva de relaciones de servicio de duración determinada para responder a necesidades permanentes y estables en materia de personal, a pesar de que para llevar a cabo tales renovaciones se aleguen causas de nombramiento previstas en la legislación. Aun existiendo razones objetivas que permitan la renovación de sucesivos contratos de trabajo de duración determinada, ello debe controlarse por los tribunales, que serán quienes deban determinar si existe una situación objetiva que justifique la obligación de crear plantilla fija, porque, si es así, deberá procederse a cubrir esas plazas a través de los procedimientos legalmente establecidos. 
c) La organización efectiva, dentro de los plazos exigidos, de procesos selectivos que tengan por objeto la provisión definitiva de las plazas ocupadas provisionalmente por empleados públicos con una relación de servicio de duración determinada es una medida adecuada para prevenir la utilización abusiva de sucesivos contratos o relaciones laborales de duración determinada. Por el contrario, cuando la organización no resulte efectiva y adecuada para el fin previsto, deberá sancionarse tal actuación, creando un efecto negativo en el empleador. Además, debe repararse a los empleados que hayan podido sufrir el abuso de la concatenación de contratos temporales, porque, de lo contrario, la organización de los procesos selectivos no se considerará suficiente.

En la normativa española se prevé la organización efectiva de tales procesos, y respecto al personal laboral se responsabiliza ex Ley 3/2017 a los culpables de vulnerar las medidas establecidas para limitar y prevenir los abusos en la contratación temporal. En lo que se refiere a la reparación de los empleados que han sufrido el abuso que conlleva la concatenación de contratos temporales, no existe criterio legal que pueda concretar el contenido y alcance de dicha reparación. Pero si se entiende que con dichos procesos se procederá a cubrir plazas, lo lógico es que, conforme a lo que señala actualmente la jurisprudencia, en el caso del personal laboral interino por vacante no quepa indemnización alguna y en los supuestos de indefinidos no fijos y funcionarios interinos la indemnización se corresponda con la prevista para la extinción de contratos de trabajo temporales en el artículo 49.1.c) del TRLET.

d) La transformación de los empleados públicos que hayan sido nombrados de manera abusiva en el marco de sucesivas relaciones de servicio de duración determinada en indefinidos no fijos no es una medida adecuada para prevenir y sancionar la temporalidad en las Administraciones públicas, a pesar de que el TJUE deje tal consideración en manos de los tribunales internos, porque la figura de los indefinidos no fijos prolonga en el tiempo situaciones en origen fraudulentas, atentando contra el interés general y, en su caso, ante su eventual amortización, generando un coste a la Administración que equivale a la indemnización por despido objetivo.

e) El TJUE considera que una indemnización equivalente a la abonada en caso de despido improcedente puede constituir una medida adecuada para prevenir y sancionar la utilización abusiva de sucesivos contratos o relaciones laborales de duración determinada en las Administraciones públicas, siempre y cuando, así lo consideren los tribunales internos y sirva para compensar el abuso sufrido. Sin embargo, debe partirse de la idea lógica de que la causa del daño causado es el funcionamiento irregular de la Administración pública del que se ha beneficiado quien no cumple los requisitos para continuar siendo empleado público o quien nunca los cumplió, en el caso de los indefinidos no fijos. 
f) El hecho de que un empleado público haya consentido el establecimiento o la renovación de sus relaciones de servicio de duración determinada por parte de la Administración pública no enerva el carácter abusivo de la situación.

g) Los tribunales internos no están obligados a dejar sin aplicación una disposición de su Derecho interno contrario a la Cláusula 5 del Acuerdo Marco que se adjunta a la Directiva 1999/70/CE. Pero tomando en consideración la totalidad de su Derecho interno y aplicando los métodos de interpretación reconocidos por este, deben hacer todo lo que sea de su competencia a fin de garantizar la plena efectividad del Acuerdo Marco y alcanzar una solución conforme con el objetivo perseguido por esta.

\section{Bibliografía}

Alfonso Mellado, C.L. (2016): «La reversión a la gestión directa de servicios públicos: problemas laborales (atención especial a las entidades locales y a las sociedades mercantiles de capital público)», Revista de Derecho Social, 73, 25-44.

Arufe Varela, Alberto (2015): «Los trabajadores indefinidos no fijos al servicio de las Administraciones públicas: una anomalía jurisprudencial y legal», Revista General de Derecho del Trabajo y de la Seguridad Social, 40, 1-27.

Beltrán de Heredia Ruiz, Ignasi (2012): “Amortización simple” de indefinidos no fijos: tampoco procede en las extinciones anteriores a la reforma de 2012», Civitas: Revista Española de Derecho del Trabajo, 173, BIB 20151677.

Boltaina Bosch, Xabier (2011): «La diversidad de regímenes jurídicos de los empleados públicos», Revista Aragonesa de Administración Pública, extra 13, 129-169.

Desdentado Bonete, Aurelio (2018): «Los indefinidos no fijos: ¿una historia interminable o una historia terminada?», Revista de Información Laboral, 10, BIB 2018\13435, $1-32$.

Desdentado Bonete, Elena (2016): Las relaciones laborales en las Administraciones públicas, Albacete, Bomarzo, 2. ${ }^{\text {a edición. }}$

Fernández Avilés, José Antonio (2017): «Aspectos laborales de la reversión de servicios públicos», Revista de Trabajo y Seguridad Social. Centro de Estudios Financieros, 407, $5-13$.

Fondevila Antolín, Jorge (2018): «Algunas propuestas para una necesaria revisión de la cuestionable doctrina judicial del reconocimiento, al personal laboral temporal y funcionarios interinos, de la condición de "indefinidos no fijos" ", Gabilex: Revista del Gabinete Jurídico de Castilla-La Mancha, 13, 15-83.

Instituto Nacional de Administración Pública (2005): Informe de la Comisión para el estudio y preparación del Estatuto Básico del Empleado Público, Madrid, Instituto Nacional de Administración Pública.

López Balaguer, Mercedes (2018): «Reversión de contrata a la Administración pública con recuperación de la infraestructura esencial al servicio: SSTS de 19 de septiembre de 2017 (Rec. 2832, 2650, 2612, 2629/2016)", Civitas: Nueva Revista Española de Derecho del Trabajo, 205, BIB 2018\5868, 1-13. 
Madrid YagüE, Pilar (2012): «Contratación administrativa y empresas de trabajo temporal», Revista General de Derecho del Trabajo y de la Seguridad Social, 28, 164-191.

Méndez Sebastián, Paz (2017): «La batalla entre el ser y el deber ser en la aplicación horizontal del principio de igualdad. A propósito de la problemática indemnización de los interinos", Civitas: Nueva Revista Española de Derecho del Trabajo, 194, 165-201

Recuerda Girela, Miguel Ángel y Fernández Depuech, Lucía (2013): «Los contratos administrativos que encubren relaciones laborales o tienen por objeto funciones reservadas al personal funcionario (parte I)", Revista General de Derecho Administrativo, $32,1-28$.

Rodríguez Escanciano, Susana (2017): «Temporalidad en el empleo público: abusos más frecuentes y reacciones del Tribunal de Justicia de la Unión Europea», Revista de Trabajo y Seguridad Social. Centro de Estudios Financieros, 407, 17-56.

Selma Penalva, Alejandra (2006): «¿Cuál es el cauce procedimental oportuno en la contratación administrativa? Sentencia del TSJ de Madrid, Sala de lo Social, de 30 de enero de 2006", Revista Doctrinal Aranzadi Social, BIB 2006\1835, 1-6.

Selma Penalva, Alejandra (2018): «El polémico derecho a la promoción profesional de los trabajadores indefinidos no fijos. Comentario a la Sentencia N.o 352/2018 del Tribunal Supremo, Sala 4. a, de lo Social, 2 de abril de 2018», IUSLabor, 2, 294-307.

Villanueva Puertollano, Ricardo (2012): El empleo público local: una visión global. Análisis práctico de las relaciones funcionariales y laborales, Madrid, Editorial Académica Española. 